\title{
Depression and anxiety in expectant and new fathers: Iongitudinal findings in Australian men
}

\author{
Liana S. Leach, Andrew Mackinnon, Carmel Poyser and A. Kate Fairweather-Schmidt
}

\section{Background}

Despite growing interest in men's perinatal mental health, we still know little about whether becoming a new father is associated with increases in psychological distress.

\section{Aims}

To use prospective Iongitudinal data to investigate whether becoming a first-time expectant (partner pregnant) and/or new father (child $<1$ year) is associated with increases in depression and anxiety.

\section{Method}

Men were aged 20-24 years at baseline $(n=1162)$. Levels of depression and anxiety were measured at four time points over 12 years. Over this time, 88 men were expectant fathers, 108 men were new fathers and 626 men remained non-fathers.

\section{Results}

Longitudinal mixed models showed no significant increase in depression or anxiety as a function of expectant or new fatherhood, as compared with pre-fatherhood levels.

\section{Conclusions}

Our findings suggest that, generally, expectant and new fathers are not at greater risk of depression or anxiety. Future epidemiological research should continue to identify men who are most (and least) at risk to focus resources and assistance most effectively.

\section{Declaration of interest}

None.

\section{Copyright and usage}

(c) The Royal College of Psychiatrists 2015.
The status of men's mental health during the perinatal period has become the focus of recent research. ${ }^{1-3}$ Beyond concern for new fathers themselves, this interest is, in part, because of the potential negative impact fathers' poor mental health may have on the wellbeing of their partner and children. ${ }^{1,4}$ Despite growth in the available research, it is still uncertain whether the perinatal period is a time of increased risk for men's depression and anxiety. This uncertainty is chiefly because of a lack of prospective, longitudinal research. Point-prevalence (cross-sectional) estimates have been compared between post-partum men and men in the general population, in an attempt to examine whether the post-natal period is a time of heightened risk. A meta-analysis by Paulson \& Bazemore $^{2}$ reported pooled prevalence estimates of post-partum depression as $8 \%$ from birth to 3 months, $26 \%$ from 3 to 6 months and 9\% from 6 to 12 months. These can be compared with estimates in the general male population (for example the 12-month prevalence of any affective disorder for Australian men aged $25-34$ is $7.0 \%$ and aged $35-44$ is $8.4 \% ;^{5}$ 1-week prevalence of mixed anxiety and depressive disorder for UK men aged $25-34$ is $7.4 \%$ and aged $35-44$ is $7.4 \%{ }^{6}$ ). There are several problems with this approach. There is substantial heterogeneity in reported prevalence rates of depression in post-partum men, principally because of differences in sample selection and measurement of psychological disorder, limiting confidence in pooled estimates. ${ }^{2}$ The inclusion of new, existing and expectant fathers in general population estimates also makes comparisons between post- partum men and 'general' men problematic. Ultimately, new (and expecting) fathers are a particular subgroup within the broader population of men and are likely to differ from them in a myriad of ways. Changes in mental health associated with new fatherhood are best evaluated using prospective, longitudinal designs. By following the same sample of men over time, and applying the same methods at each occasion of measurement, many of the biases concerned with selection and measurement differences are either eliminated or controlled. Several longitudinal studies have examined change in depression and/or anxiety during the perinatal period. ${ }^{7-12}$ However, no previous study has included pre-pregnancy data and a comparison group of non-fathers. Pre-pregnancy data (covering the period prior to expectant paternity) are required to determine if men's mental health differs from before they began the transition to fatherhood. The presence of a comparison control group allows us to both account for (i.e. adjust statistically) and observe the mental health of men who do not become fathers.

The current study utilised longitudinal, population-based data to investigate whether first-time expectant or new fatherhood is associated with an increase in levels of depression and/or anxiety. The transition to fatherhood (first child) is of interest given this time may be particularly stressful as a result of change in partner roles and responsibilities. Data about participants' life circumstances (such as fatherhood status, marital status, socioeconomic factors, substance use, social support and role strain) and mental health were recorded on four occasions, including prior to, during and after the transition to fatherhood. The prospective design of the study, with the unique inclusion of baseline pre-transition data, enables resolution of the methodological issues described above.

\section{Method}

\section{Study sample}

Data were from four waves of the Personality and Total Health (PATH) Through Life Survey, a longitudinal, population-based survey assessing the health and well-being of the residents of Canberra and Queanbeyan (New South Wales) in Australia. ${ }^{13}$ The PATH project is undertaken by the Centre for Research on Ageing, Health and Wellbeing, at The Australian National University. PATH follows three cohorts of participants, initially aged 20-24, 40-44 and 60-64, interviewing them once every 4 years. Analyses for the current study included data from men in the 20s cohort $(n=1162)$. Over the four waves of interviews, 88 men were first-time expectant fathers at the time of interview and 108 men were first-time new fathers (i.e. had one child aged 
less than 1) (Table 1). First-time fathers were the focus of the current study, as the primary aim was to investigate the transition to fatherhood. At wave 1,61 men were already fathers whereas 626 men remained non-fathers (never fathers) across all available waves of data collected (observed). An additional 279 men became fathers over the 12-year period, but as their child was older than 1 at the date of interview, were not observed and coded as 'new fathers'.

\section{Study procedure}

At wave 1 (collected in the year 2000) participants were randomly selected from the Canberra and Queanbeyan electoral rolls. With few exceptions, Australians aged 18 and above are required to register on the electoral roll. To contact participants aged 20-24, an introductory letter explaining the study was sent to 12414 people listed as 20- to 29-year-olds on the electoral roll. In the 20 s age group, a total of 4105 people were in the correct age range and could be located, and $58.6 \%$ agreed to be interviewed $(n=2404,48.3 \%$ men). At wave 2 (collected in 2003), 89\% of participants were re-interviewed ( $n=2139,47.4 \%$ men). At wave 3 (collected in 2007), 82\% of participants in the 20s cohort from wave 1 were re-interviewed $(n=1978,46.5 \%$ men). At wave 4 (collected in 2011) 53\% of participants from wave 1 were re-interviewed ( $n=1286,42.5 \%$ men). Further information about the PATH sample has been previously published. ${ }^{13}$ The PATH study was approved by the Australian National University's Human Research in Ethics Committee.

\section{Measures}

\section{Fatherhood status}

Men's fatherhood status at each wave was represented by three indicator variables: (a) expectant fatherhood identified the wave at which men were first-time expectant fathers as ' 1 ' and as ' 0 ' at all other waves;

(b) new fatherhood identified the wave at which men were firsttime fathers (with a child less than 1 year old) as ' 1 ' and as ' 0 ' at all other occasions;

(c) ongoing fatherhood identified the wave at which men were fathers, regardless of child age or number of children. This variable coded any time-point at which men were fathers as ' 1 ' and any time when they were not fathers as ' 0 '.

In addition, a time invariant, between-person index (never fathers) identified men who were not fathers at any time during the study period (coded 1), as opposed to all other men who were fathers at some point (coded 0 ). Table 2 provides several examples of how individual men were coded on these variables depending on their fatherhood status across the four time-points. Table 3 also includes an additional grouping of already fathers (men who were fathers at wave 1). This group was not explicitly coded and included in the subsequent mixed-models analyses, as the analyses focus on the transition to fatherhood. However, as baseline differences in this group of young fathers and the other men in the sample may be of interest, their wave 1 data are shown in Table 3.

\section{Mental health}

Depression and anxiety were measured using the Goldberg Depression and Anxiety Scales. ${ }^{14}$ Each scale contains nine binary items (yes, 1 ; no, 0 ) summed to yield scale scores ranging from 0 to 9 . The scales have been found to effectively detect elevated levels of depression and anxiety in community samples. ${ }^{15}$ General mental health was measured using the 12-item Short Form Health Survey (SF-12) mental component. ${ }^{16}$ The SF-12 has previously been found to have good reliability, validity and consistency. ${ }^{17}$ A scoring system derived from population norms produces a

\begin{tabular}{|c|c|c|c|c|c|}
\hline & $\begin{array}{l}\text { Wave } 1 \\
(n=1162)\end{array}$ & $\begin{array}{l}\text { Wave } 2 \\
(n=1013)\end{array}$ & $\begin{array}{l}\text { Wave } 3 \\
(n=920)\end{array}$ & $\begin{array}{l}\text { Wave } 4 \\
(n=548)\end{array}$ & Total \\
\hline Expectant fathers $^{a}$ & 12 & 23 & 31 & 22 & 88 \\
\hline New fathers ${ }^{a}$ & 11 & 27 & 41 & 29 & 108 \\
\hline
\end{tabular}

\begin{tabular}{|c|c|c|c|c|}
\hline & Wave 1 & Wave 2 & Wave 3 & Wave 4 \\
\hline \multicolumn{5}{|l|}{ Expectant father at wave $2^{b}$} \\
\hline Expectant father status & 0 & 1 & 0 & 0 \\
\hline New father status & 0 & 0 & 0 & 0 \\
\hline Ongoing Father & 0 & 0 & 1 & 1 \\
\hline Never father & 0 & 0 & 0 & 0 \\
\hline \multicolumn{5}{|l|}{ New father at wave $2^{\mathrm{b}}$} \\
\hline Expectant father status & 0 & 0 & 0 & 0 \\
\hline New fatherhood status & 0 & 1 & 0 & 0 \\
\hline Ongoing fatherhood & 0 & 0 & 1 & 1 \\
\hline Never father & 0 & 0 & 0 & 0 \\
\hline \multicolumn{5}{|l|}{ Never a father ${ }^{c}$} \\
\hline Expectant fatherhood status & 0 & 0 & 0 & 0 \\
\hline New fatherhood status & 0 & 0 & 0 & 0 \\
\hline Ongoing fatherhood & 0 & 0 & 0 & 0 \\
\hline Never father & 1 & 1 & 1 & 1 \\
\hline \multicolumn{5}{|c|}{$\begin{array}{l}\text { a. ' } 1 \text { ' indicates a positive status (for example as an expectant father), and ' } 0 \text { ' indicates a negative status (for example not an expectant father). } \\
\text { b. Time varying variables } \\
\text { c. Time invariant variable. }\end{array}$} \\
\hline
\end{tabular}


mean of approximately 50 and a standard deviation of 10 when a normal population is assessed. Higher scores indicate better mental health.

\section{Covariates}

Adjustments were made for several factors subject to change across the transition to parenthood potentially associated with mental health. These included age, marital status (married, de facto, separated/divorced, never married), education level (total years) and employment status (employed, unemployed, not in the labour force). A measure of financial hardship asked whether respondents had gone without things they needed because of financial problems in the past year (never, 0; sometimes/often, 1). A number of lifestyle and social factors were also included in the analyses. Smoking was assessed by asking 'Do you currently smoke?' Possible responses were either ' 1 ' yes or ' 0 ' no. Alcohol use was measured using the frequency and quantity items from the Alcohol Use Disorders Identification Test (AUDIT). ${ }^{18}$ Participants were then classified into one of three categories based on the National Health and Medical Research Council (NHMRC) (2001) guidelines: (a) non-drinkers or occasional drinkers (0-13 standard drinks per week for men and 0-7 for women), (b) moderate drinkers (14-27 drinks for men and 8-13 for women) or (c) hazardous or harmful drinkers (28 or more drinks for men and 14 or more for women). The SF-12 physical component was used as a measure of physical health. ${ }^{16,19}$ The SF-12 was designed for use in population samples and epidemiological research. The scale asks about participants' functioning in the 4 weeks prior to interview. A standardised scoring system was derived to produce a mean of 50 and standard deviation of 10 when used in normal populations. Role strain was assessed in two domains: housework and financial provision. Responses were coded as either 1: 'about $75 \%$ or more responsible' or 0 : 'about $50 \%$ or less responsible'. Positive social support from family and friends were assessed using a series of items developed by Schuster et al. ${ }^{20}$ Scores from the items were added providing two scales (one for family and another for friends), ranging from 0 to 6 .

\section{Analysis}

Differences between the fatherhood groups at baseline were tested using ANOVA and chi-squared tests. Random intercept longitudinal models (mixed models) were then used to test whether levels of depression and anxiety changed in association with becoming an expectant or a new father. These models permitted the intercept to vary for individuals (reflecting the different initial mental health scores for individuals). The longitudinal methods used do not require complete data on the outcome measure, thus maximising the number of observations available for analysis.

The mixed-models analysis comprised a series of stages. Model A regressed depression/anxiety on time-varying fatherhood status (expectant father and new father), while adjusting for age (at baseline), time and ongoing fatherhood status. Including the latter term is important, as it ensures that the effects for expectant and new fatherhood represent these 'acute' states or time periods in comparison (or reference) with before men had children. This model also included a term for the time-invariant indicator never father to account for differences between men who were fathers at some time point and men who were never fathers during the study period. Model B included the demographic and socioeconomic time-varying covariates: marital status, education level, employment status and financial hardship. Finally, Model C included the lifestyle and social time-varying covariates: smoking status, alcohol consumption, physical health, role-strain in terms of responsibility for household tasks and financial provision, and level of support from family and friends.

A series of follow-up analyses were conducted. The first included the covariate 'sleeping poorly' to examine whether adjusting for sleep deprivation altered the findings (as expectant and new fathers may experience more disturbed sleep than other men). The second used a general measure of mental health (SF-12) as an outcome, to assess whether the findings changed if a broader measure of psychological distress was adopted. Finally, sensitivity analyses using only respondents with complete data examined whether attrition had an impact on the findings. All analyses were conducted using Stata 10.0. Participants with missing data were minimal (range $0-3.7 \%$ of items within waves) and so were excluded on an analysis-by-analysis basis.

\section{Results}

\section{Descriptive statistics}

Baseline characteristics disaggregated by fatherhood status and for all the men in the study, are shown in Table 3. ANOVA and chi-squared analyses showed several significant differences between the three fatherhood groups of primary interest (expectant father at any wave; new father at any wave; never fathers). Men who did not go on to be fathers (never fathers), had poorer mental health than men who became fathers at a later time point, with significantly greater levels of depression $(F(3,877)=4.47, \quad P=0.004) \quad$ and anxiety $(F(3,877)=3.45$, $P=0.016)$ and poorer overall mental health $(F(3,877)=4.98$, $P=0.002)$. Also of interest are men who were already fathers at baseline. Although this group is not the focus of the current study, these men showed some interesting differences in baseline characteristics compared with the other men. They were significantly older $(F(3,882)=12.89, P<0.001)$, were more likely to be married $\left(\chi^{2}(9)=231.10, P<0.001\right)$, had fewer years of education $(F(3,879)=6.60, P<0.001)$, were more likely to have experienced recent financial hardship $\left(\chi^{2}(3)=9.92, P=0.019\right)$, infrequently or never drinking alcohol $\left(\chi^{2}(6)=15.72, P=0.015\right)$, had less support from friends $(F(3,876)=3.25, P=0.021)$ and were more likely to be experiencing role-strain providing financially for their household $\left(\chi^{2}(3)=56.40, P<0.001\right)$. They also had poorer mental health than men who became fathers at a later time point, with significantly greater levels of depression $(F(3,877)=4.47, \quad P=0.004) \quad$ and anxiety $(F(3,877)=3.45$, $P=0.016)$ and poorer overall mental health $(F(3,877)=4.98$, $P=0.002)$.

\section{Expectant and new fatherhood transitions}

Figure 1 shows predicted trajectories for depression and anxiety across all four waves for three fatherhood categories: (a) men who were first-time expectant fathers at the time of interview (either wave 2 or 3), (b) men who were first-time new fathers at the time of interview (either wave 2 or 3 ), and (c) men who did not become fathers (never fathers) over the study period. It is evident that mean depression and anxiety status vary little across time by change in fatherhood status. Although levels of depression do appear to increase when men are new fathers at both waves 2 and 3, this increase in depression is not significant (as is described in Table 4, discussed below). The figure also shows that men who were 'never fathers' during the study consistently experienced higher levels of both depression and anxiety than the other men.

Table 4 presents results (coefficients and standard errors) from the mixed models examining the association between fatherhood 


\begin{tabular}{|c|c|c|c|c|c|}
\hline & $\begin{array}{l}\text { All men }{ }^{\mathrm{a}} \\
(n=1162)\end{array}$ & $\begin{array}{l}\text { Never father }{ }^{b} \\
\quad(n=626)\end{array}$ & $\begin{array}{c}\text { Expectant father } \\
\text { (at any wave) })^{\mathrm{c}}(n=88)\end{array}$ & $\begin{array}{l}\text { New father (at any } \\
\text { wave }^{\mathrm{d}}(n=108)\end{array}$ & $\begin{array}{c}\text { Already fathers } \\
\text { (at baseline) }^{\mathrm{e}}(n=61)\end{array}$ \\
\hline Age, mean (s.d.) & $22.5(1.5)$ & $22.3(1.5)$ & $22.7(1.4)$ & $22.7(1.5)$ & $23.4(1.4)$ \\
\hline \multicolumn{6}{|l|}{ Partner status, $n(\%)$} \\
\hline Married & $71(6.1)$ & $6(1.0)$ & $10(11.4)$ & $12(11.1)$ & $20(32.8)$ \\
\hline De facto & $144(12.4)$ & $43(6.9)$ & $16(18.2)$ & $25(23.1)$ & $23(37.7)$ \\
\hline Separated/divorced & $3(0.3)$ & $1(0.2)$ & $0(0.0)$ & $0(0.0)$ & $2(3.3)$ \\
\hline Never married & $939(80.8)$ & $573(92.0)$ & $62(70.5)$ & $21(65.7)$ & $16(26.2)$ \\
\hline Years of education, mean (s.d.) & $14.5(1.5)$ & $14.4(1.5)$ & $14.7(1.6)$ & $14.6(1.5)$ & $13.7(1.4)$ \\
\hline \multicolumn{6}{|l|}{ Employment status, $n$ (\%) } \\
\hline Employed & $993(85.5)$ & $516(82.8)$ & $79(89.8)$ & $98(90.7)$ & $51(83.6)$ \\
\hline Unemployed & $78(6.7)$ & $53(8.5)$ & $3(3.4)$ & $3(2.8)$ & $7(11.5)$ \\
\hline Not in labour force & $86(7.4)$ & $54(8.7)$ & $6(6.8)$ & $7(6.5)$ & $3(4.9)$ \\
\hline \multicolumn{6}{|l|}{ Financial hardship, $n$ (\%) } \\
\hline $0(\mathrm{no})$ & $873(75.6)$ & $498(75.4)$ & $71(80.7)$ & $86(79.6)$ & $37(60.7)$ \\
\hline 1 (sometimes/often) & $281(24.4)$ & $153(24.6)$ & $17(19.3)$ & $21(19.4)$ & $24(39.3)$ \\
\hline \multicolumn{6}{|l|}{ Smoke, $n$ (\%) } \\
\hline 0 (no) & $787(68.1)$ & $470(65.9)$ & $70(79.5)$ & $78(72.9)$ & $40(65.6)$ \\
\hline 1 (yes) & 368 (31.9) & $212(34.1)$ & $18(20.5)$ & $29(21.7)$ & $27(34.4)$ \\
\hline \multicolumn{6}{|l|}{ Alcohol, $n$ (\%) } \\
\hline Never/occasional & $320(27.7)$ & $188(30.2)$ & $23(26.1)$ & $17(15.9)$ & $23(37.7)$ \\
\hline Moderate & $764(65.5)$ & 395 (63.5) & $60(68.2)$ & $87(81.3)$ & $35(57.4)$ \\
\hline Heavy & $71(6.1)$ & $39(6.3)$ & $5(5.7)$ & $3(2.8)$ & $3(4.9)$ \\
\hline Physical health (0-100), mean (s.d.) & $53.4(6.4)$ & $53.4(6.4)$ & $54.2(5.56)$ & $53.7(5.9)$ & $52.9(6.6)$ \\
\hline \multicolumn{6}{|l|}{ Role-strain housework, $n(\%)$} \\
\hline $0(\mathrm{no})$ & $931(80.7)$ & 485 (78.1) & $74(84.1)$ & $93(86.9)$ & $47(77.0)$ \\
\hline 1 (yes) & $223(19.3)$ & $136(21.9)$ & $14(13.6)$ & $14(13.1)$ & $14(33.0)$ \\
\hline \multicolumn{6}{|l|}{ Role-strain provision, $n(\%)$} \\
\hline $0(\mathrm{no})$ & $925(79.6)$ & $518(83.4)$ & $76(86.4)$ & $85(79.4)$ & $27(44.3)$ \\
\hline 1 (yes) & $229(19.7)$ & $103(16.6)$ & $12(13.6)$ & $22(20.6)$ & $34(55.7)$ \\
\hline Support friends (0-6), mean (s.d.) & $4.84(1.3)$ & $4.8(1.4)$ & $5.0(1.2)$ & $5.1(1.2)$ & $4.6(1.4)$ \\
\hline Support family (0-6), mean (s.d.) & $5.32(1.1)$ & $5.3(1.2)$ & $5.5(1.0)$ & $5.4(1.1)$ & $5.3(1.1)$ \\
\hline Mental health (0-100), mean (s.d.) & $48.78(9.7)$ & $47.7(10.3)$ & $50.8(7.3)$ & $50.7(8.9)$ & $49.5(9.7)$ \\
\hline Depression (0-9), mean (s.d.) & $2.58(2.3)$ & $2.8(2.4)$ & $2.0(1.9)$ & $2.2(2.1)$ & $2.7(2.3)$ \\
\hline Anxiety (0-9), mean (s.d.) & $3.19(2.6)$ & $3.3(2.6)$ & $2.7(2.6)$ & $2.8(2.5)$ & $3.5(2.6)$ \\
\hline
\end{tabular}

status and depression levels over time. Model A shows that men's depression levels were no different when they were first-time expectant fathers $(b=-0.31$, s.e. $=0.22, P=0.148)$ compared with before this time (within-person change). In other words, the coefficient shows that men scored 0.31 points lower on the depression scale when they were an expectant father compared with pre-pregnancy; however, this difference was not statistically significant. Nor were there any significant effects for men at the time they were first-time new fathers $(b=0.11$, s.e. $=0.20$, $P=0.575$ ). This initial model included fixed effects of time (wave), age, and 'ongoing fatherhood'. The latter term ensured that the effects for expectant and new fatherhood were associated with these 'acute' states or time periods in comparison with before men had children. In addition, the model incorporated a between-person term representing no experience of fatherhood (never father). This term was significant $(b=0.61$, s.e. $=0.12$, $P<0.001$ ), suggesting that individuals who were never fathers scored 0.61 points higher on the depression scale overall than those who were (or who would become) fathers at some point during the study. Models $\mathrm{B}$ and $\mathrm{C}$ included a range of additional demographic, socioeconomic, social and lifestyle covariates. Adjusting for these factors did not significantly alter the effects of expectant $(b=-0.13$, s.e. $=0.25, P=0.599)$ or new fatherhood $(b=0.36$, s.e. $=0.21, \quad P=0.091) \quad($ Model C). Although the magnitude of effect of never-father status was reduced (particularly with the inclusion of partner status and socioeconomic factors in Model B), these variables did not fully account for the higher levels of depression reported by never fathers.

The models examining the association between fatherhood circumstances and anxiety levels over time are shown in Table 5. These findings differ little from the previous results for depression. Model A found no significant effects for men at the time they were first-time expectant $(b=-0.05$, s.e. $=0.24, P=0.825)$ or new fathers $(b=-0.12$, s.e. $=0.22, P=0.604)$, compared with before these times. The model again shows that individuals who were 'never fathers' had greater levels of anxiety overall than those who were (or who would become) fathers at some point in time $(b=0.48$, s.e. $=0.14, P<0.01)$. The inclusion of covariates in Model's B and C did not alter the effects of the fatherhood variables, however, the significant effect of never fatherhood was annulled $(b=0.23$, s.e. $=0.15, P=0.152)$. The effect of never fatherhood was markedly reduced with the introduction of partner status and socioeconomic factors in Model B. 

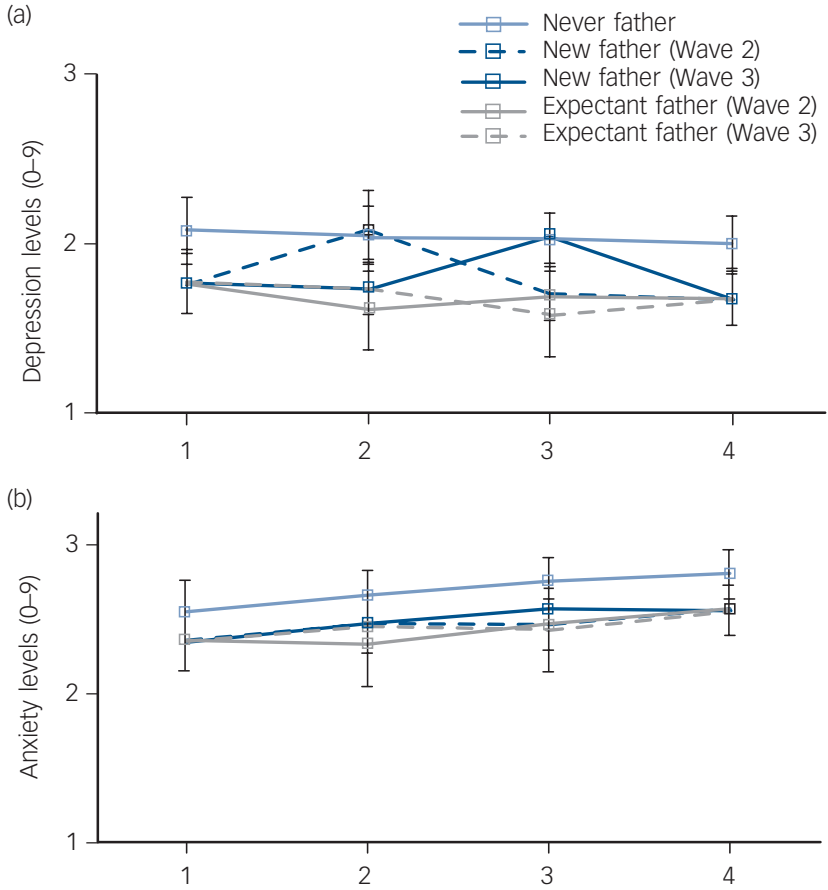

Fig. 1 Model trajectories of (a) depression and (b) anxiety for men as a function of fatherhood status on each occasion of measurement.

All categorical covariates are set to their modal categories: married, employed, no financial hardships, non-smoker, occasional alcohol use, minimal housework role-strain, minimal financial provision role-strain. Continuous covariates were set to sample mean values (age at baseline, 28; physical health, 53.22; friend support, 4.79; family support, 5.34$)$.

\section{Additional analyses}

A range of supporting analyses largely demonstrated the robustness of the results. The results for the fatherhood variables showed minimal change when a dichotomous measure of 'have you been sleeping poorly' (no, 0 ; yes, 1 ) was included in the final models as a covariate. The analyses were repeated using general mental health (SF-12) as an outcome. The results mirrored those obtained for depression and anxiety. As response bias and attrition can also influence longitudinal analysis, we repeated the analyses including only those participants with complete data $(n=519$, balanced panel). The models changed little with findings for expectant $(n=60)$, new $(n=69)$, ongoing fatherhood and never fathers remaining essentially the same. However, higher levels of baseline depression were observed in those participants who dropped out at some stage of the study $(t(1153)=2.689$, $P=0.007$ ) and specifically at wave 4 (when attrition was the highest $)(t(883)=(-2.135, P=0.033))$, compared with those who remained in the study at all waves.

\section{Discussion}

The primary goal of this study was to assess whether men were at greater risk of depression and anxiety during the perinatal period, compared with pre-fatherhood/transition levels. The results showed that men experienced no greater depression or anxiety at the time of being a first-time expectant or new father, compared with levels prior to transition to fatherhood.

The current findings are supported by a number of other studies investigating men's mental health during the perinatal period. In a population-based register study, Munk-Olesen et $a l^{21}$ concluded that use of services for psychiatric disorders was not greater for new fathers than for men in general. Other research, adopting similar analytical techniques to the current study, analysed three waves of population-level data from New Zealand $^{22}$ finding that first-time fathers had better mental health (SF-36) and less psychological distress (K-10) compared with pre-transition levels. This was also found to be the case in a recent Australian study examining change in psychological distress across ten time points. ${ }^{23}$ Two additional population-based studies, both analysing two waves of data, also showed no indication that well-being decreases for men with the birth of a first child. ${ }^{24,25}$

Other previous research has found that some men find the perinatal period to be a difficult period. Studies examining postnatal depression in men have identified several risk factors that make poor mental health more likely, including having a partner with depression and poor intimate relationship satisfaction. ${ }^{3}$ However, there is also evidence that many men experience positive emotions such as happiness and pride as part of the transition to fatherhood. ${ }^{26}$ It is possible that there is considerable variation (both between and within individuals) in men's emotional responses during both their partner's pregnancy and the first year of fatherhood. Results of the present study may be an indication that the positives and the negatives 'balance one another out', when a population-based approach is taken.

Interestingly, the current findings suggest that 'never fathers' were the most psychologically distressed group of men. For the most part, potentially mediating factors accounted for this finding. The inclusion of partner status and other socioeconomic resources as covariates substantially reduced associations between never being a father and both depression and anxiety. The benefits of marriage and family relationships for men's psychological wellbeing $^{27}$ are reiterated by this finding, and is consistent with research showing that men with mental health problems are less likely to have a partner and children. ${ }^{5}$

\section{Limitations and strengths}

There are a number of limitations. Diagnostic measures of depression and anxiety (i.e. mental disorders) were not available. The effects of expectant and new fatherhood over time within pregnancy and the post-partum period (for example 1-3 months postpartum) could not be assessed because of the sample size available: for instance, anxiety in the first trimester may dissipate as the pregnancy progresses or vice versa. Related to this point, data from individuals in the PATH study were collected every 4 years. Therefore, other life circumstances that affect mental health may have intervened in the interim periods. The experience of new fatherhood was not assessed beyond the age of 36, as the PATH cohort was aged 32-36 at wave 4. Although this age-range captures the arrival of most men's first child (the median age of all fathers in Australia was 33.0 years in $2012^{28}$ ), it may be that men older than 36 undertaking the transition to fatherhood have a different experience. Related to this point, we had less data on older first-time expectant/new fathers as attrition rates increased over the life of the study and particularly in wave 4. Given supplementary analyses showed that men who dropped out at wave 4 had higher rates of baseline depression, it is possible that some men at the greatest risk of depression are not represented. Further, the initial non-response rate $(60 \%)$ is another potential source of bias. Although at baseline sociodemographic indicators between the PATH male 20s cohort and the broader Canberra/ Queanbeyan population equivalent are not dissimilar (for example unemployment rates are comparable $(6.7 \%$ v. $8.8 \%)$ as is marital status $(6.1 \%$ v. $4.5 \%)),{ }^{29}$ the moderate initial 


\begin{tabular}{|c|c|c|c|}
\hline & Model A & Model B & Model C \\
\hline Expectant father & $-0.31(0.22)$ & $-0.05(0.22)$ & $-0.13(0.25)$ \\
\hline New father & $0.11(0.20)$ & $0.33(0.20)$ & $0.36(0.21)$ \\
\hline Ongoing father & $-0.00(0.12)$ & $0.01(0.12)$ & $-0.02(0.14)$ \\
\hline Never father & $0.61(0.12)^{\star \star * *}$ & $0.36(0.12)^{\star \star *}$ & $0.31(0.14)^{\star}$ \\
\hline Age at baseline & $-0.00(0.04)$ & $0.02(0.04)$ & $0.00(0.04)$ \\
\hline $\begin{array}{l}\text { Partner status } \\
\text { Married } \\
\text { De facto } \\
\text { Separated/divorced } \\
\text { Never married }\end{array}$ & & \begin{tabular}{l}
\multicolumn{1}{c}{$(\operatorname{Ref})$} \\
$0.24(0.11)^{\star}$ \\
$0.16(0.22)$ \\
$0.64(0.12)^{* * *}$
\end{tabular} & $\begin{array}{l}(\text { Ref) } \\
0.10(0.13) \\
0.29(0.24) \\
0.51(0.14)^{\star * *}\end{array}$ \\
\hline Years education & & $-0.11(0.03)^{\star * *}$ & $-0.06(0.03)$ \\
\hline $\begin{array}{l}\text { Employment status } \\
\text { Employed } \\
\text { Unemployed } \\
\text { Not in the labour force }\end{array}$ & & $\begin{array}{l}\text { (Ref) } \\
0.64(0.17)^{\star \star *} \\
0.21(0.16)\end{array}$ & $\begin{array}{c}\text { (Ref) } \\
0.64(0.22)^{\star \star} \\
-0.23(0.23) \\
\end{array}$ \\
\hline $\begin{array}{l}\text { Financial hardship } \\
0 \text { (no) } \\
1 \text { (sometimes/often) }\end{array}$ & & $\begin{array}{c}\text { (Ref) } \\
0.82(0.09)^{\star \star *}\end{array}$ & $\begin{array}{l}\text { (Ref) } \\
0.75(0.11)^{* * *}\end{array}$ \\
\hline $\begin{array}{l}\text { Smoking } \\
0 \text { (no) } \\
1 \text { (yes) }\end{array}$ & & & $\begin{array}{c}\text { (Ref) } \\
-0.50(0.12)^{\star * *}\end{array}$ \\
\hline $\begin{array}{l}\text { Alcohol consumption } \\
\text { Never/occasional } \\
\text { Moderate } \\
\text { Heavy }\end{array}$ & & & $\begin{array}{c}\text { (Ref) } \\
-0.03(0.11) \\
0.23(0.17)\end{array}$ \\
\hline Physical health & & & $-0.01(0.01)$ \\
\hline $\begin{array}{l}\text { Role-strain housework } \\
0 \text { (no) } \\
1 \text { (yes) }\end{array}$ & & & $\begin{array}{c}\text { (Ref) } \\
0.21(0.11)\end{array}$ \\
\hline $\begin{array}{l}\text { Role-strain provision } \\
0 \text { (no) } \\
1 \text { (yes) }\end{array}$ & & & $\begin{array}{c}\text { (Ref) } \\
-0.08(0.09)\end{array}$ \\
\hline Support friends & & & $-0.35(0.04)^{\star * *}$ \\
\hline Support family & & & $-0.21(0.04)^{* * *}$ \\
\hline Wave & $-0.08(0.03)^{\star}$ & $0.11(0.04)^{* *}$ & $-0.02(0.05)$ \\
\hline Constant & $2.39(0.87)^{* *}$ & $2.73(0.91)^{\star *}$ & $6.38(1.09)^{* * *}$ \\
\hline
\end{tabular}

non-response rate cannot be discounted as a further source of bias.

There are also limitations to the nature of the model fitted, which effectively averages effects over time. For example, new fatherhood for men with financial security may be a different experience to new fatherhood for men with few financial resources. Similarly, baby- and partner-related factors, such a baby's health/temperament, relationship quality and partner mental health have been identified as important factors that may distinguish those new fathers with and without mental health problems. ${ }^{30}$ Although assessing differences between different types of expectant/new fathers (or moderating variables) was not the focus of the current study (and was not feasible given the sample size available), this limitation highlights the need for other detailed risk factor research that identifies which men are most at risk of mental health problems during the perinatal period. Finally, although the study uses the category 'never father' to identify those who had not had children within the 12-year study period, a proportion of these men may go on to become fathers. Given the men are aged 32-36 at the last time point measured (wave 4), a longer time period is needed to more thoroughly assess the impact of never becoming a father.
There are a number of unique strengths to the current study that should be emphasised. Few previous investigations have utilised population-based data from a community sample. Uniquely, this study analysed four waves of longitudinal data, which included pre-pregnancy/fatherhood baseline data on men's mental health. Furthermore, the breadth of variables included in the PATH study allowed us to adjust for covariates that are likely to change with first-time expectant and new fatherhood status, such as role-strain (housework, provision), social support (friends, family) and alcohol use. In addition, the current study broadens what is currently known about anxiety in men during the perinatal period, a much under-researched area compared with depression.

\section{Future directions}

This study highlights a number of directions for future research regarding men's perinatal mental health. The variability of psychological responses to new fatherhood is raised as an important issue. It is likely that there is great variability in levels of depression and anxiety not only between men in this life stage, but also within individual men, depending on the time point at 
Table 5 Coefficients (and standard errors) from longitudinal random intercept regression models assessing the association between fatherhood status and anxiety ${ }^{a}(n=1162)$

\begin{tabular}{|c|c|c|c|}
\hline & Model A & Model B & Model C \\
\hline Expectant father & $-0.05(0.24)$ & $0.12(0.24)$ & $-0.12(0.27)$ \\
\hline New father & $-0.12(0.22)$ & $0.05(0.22)$ & $0.10(0.24)$ \\
\hline Ongoing father & $0.01(0.13)$ & $-0.03(0.13)$ & $-0.09(0.15)$ \\
\hline Never father & $0.48(0.14)^{* *}$ & $0.29(0.14)^{*}$ & $0.23(0.15)$ \\
\hline Age at baseline & $0.02(0.04)$ & $0.03(0.04)$ & $0.01(0.04)$ \\
\hline $\begin{array}{l}\text { Partner status } \\
\text { Married } \\
\text { De facto } \\
\text { Separated/divorced } \\
\text { Never married }\end{array}$ & & $\begin{array}{l}\quad \text { (Ref) } \\
0.17(0.13) \\
0.32(0.24) \\
0.39(0.13)^{\star *}\end{array}$ & $\begin{array}{c}\text { (Ref) } \\
0.10(0.14) \\
0.46(0.26) \\
0.29(0.16) \\
\end{array}$ \\
\hline Years education & & $-0.05(0.03)$ & $0.02(0.04)$ \\
\hline $\begin{array}{l}\text { Employment status } \\
\text { Employed } \\
\text { Unemployed } \\
\text { Not in the labour force }\end{array}$ & & $\begin{array}{l}\text { (Ref) } \\
0.59(0.19)^{\star *} \\
0.45(0.18)^{\star}\end{array}$ & $\begin{array}{l}(\text { Ref }) \\
0.66(0.25)^{* *} \\
-0.01(0.25)\end{array}$ \\
\hline $\begin{array}{l}\text { Financial hardship } \\
\qquad \begin{array}{l}0 \text { (no) } \\
1 \text { (sometimes/often) }\end{array}\end{array}$ & & $\begin{array}{c}\text { (Ref) } \\
0.97(0.10)^{\star * *}\end{array}$ & $\begin{array}{c}\text { (Ref) } \\
0.97(0.13)^{* * *}\end{array}$ \\
\hline $\begin{array}{l}\text { Smoking } \\
0 \text { (no) } \\
1 \text { (yes) }\end{array}$ & & & $\begin{array}{l}\text { (Ref) } \\
-0.67(0.13)^{\star * *}\end{array}$ \\
\hline $\begin{array}{l}\text { Alcohol consumption } \\
\text { Never/occasional } \\
\text { Moderate } \\
\text { Heavy }\end{array}$ & & & $\begin{array}{l}\text { (Ref) } \\
0.10(0.12) \\
0.07(0.19)\end{array}$ \\
\hline Physical health & & & $-0.03(0.01)^{\star * *}$ \\
\hline $\begin{array}{l}\text { Role-strain housework } \\
0 \text { (no) } \\
1 \text { (yes) }\end{array}$ & & & $\begin{array}{c}\text { (Ref) } \\
0.03(0.12)\end{array}$ \\
\hline $\begin{array}{l}\text { Role-strain provision } \\
0 \text { (no) } \\
1 \text { (yes) }\end{array}$ & & & $\begin{array}{c}\text { (Ref) } \\
-0.01(0.10) \\
\end{array}$ \\
\hline Support friends & & & $-0.27(0.04)^{* * *}$ \\
\hline Support family & & & $-0.16(0.05)^{\star \star}$ \\
\hline Wave & $0.07(0.04)^{* *}$ & $0.19(0.04)^{* * *}$ & $-0.01(0.06)$ \\
\hline Constant & $2.40(.98)^{*}$ & $2.30(1.03)^{\star}$ & $5.95(1.23)^{* * *}$ \\
\hline
\end{tabular}

which they are measured. To investigate this, data recording men's mental health at multiple time points during the perinatal period is required, as well as baseline pre-pregnancy measures. It may be that the perinatal period is characterised by a series of 'ups and downs' for most men, and that this richness of experience needs further acknowledgement.

The current findings also query how best to identify and assist men who are experiencing mental health difficulties during the perinatal period. Although universal approaches (such as attempting to screen all men in the perinatal period) are thorough, if most men are at no greater risk of poorer mental health (as the current findings suggest), this approach may not be defensible. As previously suggested for women, ${ }^{31}$ perhaps targeting men with more than one risk factor (for example unemployed and partner with depression) might better capture men at 'true' greater risk of depression and anxiety. Increased public awareness about the risk factors for men's depression and anxiety during the perinatal period is important; however, men's reluctance to seek help is a barrier that needs to be addressed.

In summary, this study finds first-time expectant and new fatherhood is not typically associated with increased levels of depression and anxiety. However, it is important to remember that some new/expectant men will be at greater risk. Future risk-factor research should examine how we can best identify these men and offer treatment. Further work is also needed to replicate the current results and apply these findings to prevention and intervention strategies in a meaningful way.

Liana S. Leach, PhD, Centre for Research on Ageing, Health and Wellbeing, The Australian National University, Canberra; Andrew Mackinnon, PhD, Orygen Youth Health Research Centre, The University of Melbourne, Parkville; Carmel Poyser, BSC, MSC, Centre for Research on Ageing, Health and Wellbeing, The Australian National University, Canberra; A. Kate Fairweather-Schmidt, PhD, Centre for Research on Ageing, Health and Wellbeing, The Australian National University, Canberra and School of Psychology, Flinders University, Adelaide, Australia

Correspondence: Liana S. Leach, Centre for Research on Ageing, Health and Wellbeing, The Australian National University, Canberra, 0200, ACT, Australia. Email: Liana.Leach@anu.edu.au

First received 27 Mar 2014, final revision 14 Aug 2014, accepted 29 Sep 2014

\section{Funding}

This work was supported by a Movember funded beyondblue (Australia) National Priority Driven Research grant, round 2011 (LEAC11NPD). L.S.L. is funded by an Australian National 
Health and Medical Research Council (NHMRC) Early Career Fellowship \#1035803. The PATH through Life Project is also funded by an NHMRC Grants 973302, 179805 and 418039.

\section{Acknowledgements}

We thank the study participants, PATH interviewers, Trish Jacomb and Karen Maxwell. W would also like to acknowledge the contribution of the chief investigators of the PATH Project: Kaarin Anstey, Peter Butterworth, Nic Cherbuin, Helen Christensen and Simon Easteal.

\section{References}

1 Bradley R, Slade P. A review of mental health problems in fathers following the birth of a child. J Reprod Infant Psychol 2011; 29: 19-42.

2 Paulson JF, Bazemore SD. Prenatal and postpartum depression in fathers and its association with maternal depression: a meta-analysis. JAMA 2010; 303 : 1961-9.

3 Wee KY, Skouteris H, Pier C, Richardson B, Milgrom J. Correlates of ante- and postnatal depression in fathers: a systematic review. J Affect Disord 2011; 130: 358-77.

4 Ramchandani P, Stein A, Evans J, O'Connor TG. Paternal depression in the postnatal period and child development: a prospective population study. Lancet 2005; 365: 2201-5.

5 Australian Bureau of Statistics. National Survey of Mental Health and Wellbeing: Summary of Results (cat 4326.0). Australian Bureau of Statistics, 2007.

6 McManus $\mathrm{S}$, Meltzer $\mathrm{H}$, Brugha $\mathrm{T}$, Bebbington $\mathrm{P}$, Jenkins R. Adult Psychiatric Morbidity in England, 2007. National Centre for Social Research, 2009.

7 Ballard CG, Davis R, Cullen PC, Mohan RN, Dean C. Prevalence of postnatal psychiatric morbidity in mothers and fathers. Br J Psychiatry 1994; 164: 782-8.

8 Buist A, Morse CA, Durkin S. Men's adjustment to fatherhood: implications for obstetric health care. J Obstet Gynecol Neonatal Nurs 2003; 32: 172-80.

9 Condon JT, Boyce P, Corkindale CJ. The First-Time Fathers Study: a prospective study of the mental health and wellbeing of men during the transition to parenthood. Aust N Z J Psychiatry 2004; 38: 56-64.

10 Escribà-Agüir V, Artazcoz L. Gender differences in postpartum depression: longitudinal cohort study. J Epidemiol Community Health. 2011; 65: 320-6.

11 Figueiredo B, Conde A. Anxiety and depression symptoms in women and men from early pregnancy to 3-months postpartum: parity differences and effects. J Affect Disord 2011; 132: 146-57.

12 Matthey S, Barnett B, Ungerer J, Waters B. Paternal and maternal depressed mood during the transition to parenthood. J Affect Disord 2000; 60: 75-85.

13 Anstey KJ, Christensen $\mathrm{H}$, Butterworth $\mathrm{P}$, Easteal $\mathrm{S}$, Mackinnon $\mathrm{A}$, Jacomb $\mathrm{T}$ et al. Cohort profile: the PATH through life project. Int J Epidemiol 2012; 41 951-60

14 Goldberg D, Bridges K, Duncan-Jones P, Grayson D. Detecting anxiety and depression in general medical settings. BMJ 1988; 297: 897-9.
15 Mackinnon A, Christensen $H$, Jorm AF, Henderson AS, Scott R, Korten AE. A latent trait analysis of an inventory designed to detect symptoms of anxiety and depression using an elderly community sample. Psychol Med 1994; 24: 977-86

16 Ware J, Jr, Kosinski M, Keller SD. A 12-Item Short-Form Health Survey: construction of scales and preliminary tests of reliability and validity. Med Care 1996; 34: 220-33.

17 Haywood KL, Garratt AM, Fitzpatrick R. Quality of life in older people: a structured review of generic self-assessed health instruments. Qual Life Res 2005; 14: 1651-68.

18 Saunders JB, Aasland OG, Babor TF, de la Fuente JR, Grant M. Development of the Alcohol Use Disorders Identification Test (AUDIT): WHO collaborative project on early detection of persons with harmful alcohol consumption-II. Addict 1993; 88: 791-804.

19 Ware JE, Kosinski M. Interpreting SF-36 summary health measures: response. Qual Life Res. 2001; 10: 405-13; discussion 15-20.

20 Schuster TL, Kessler RC, Aseltine RH, Jr. Supportive interactions, negative interactions, and depressed mood. Am J Community Psychol 1990; 18 423-38.

21 Munk-Olsen T, Laursen TM, Pedersen CB, Mors O, Mortensen PB. New parents and mental disorders: a population-based register study. JAMA 2006; 296: 2582-9.

22 McKenzie SK, Carter K. Does transition into parenthood lead to changes in mental health? Findings from three waves of a population based panel study. J Epidemiol Community Health 2013; 67: 339-45.

23 Leach L, Olesen S, Butterworth P, Poyser C. New fatherhood and psychological distress: a longitudinal study of Australian men. Am J Epidemiol 2014; 180: 582-589.

24 Keizer R, Dykstra PA, Poortman AR. The transition to parenthood and wellbeing: the impact of partner status and work hour transitions. J Fam Psychol 2010; 24: 429-38.

25 Nomaguchi KM, Milkie MA. Costs and rewards of children: the effects of becoming a parent on adults' lives. J Marriage Fam 2003; 65: 356-74.

26 Genesoni L, Tallandini MA. Men's psychological transition to fatherhood: an analysis of the literature, 1989-2008. Birth 2009; 36: 305-18.

27 Bartlett EE. The effects of fatherhood on the health of men: a review of the literature. J Mens Health Gend 2004; 1: 159-69.

28 Australian Bureau of Statistics. Births (cat. No. 3301.0). Australian Bureau of Statistics, 2012

29 Australian Bureau of Statistics. 2001 Census Data (cat 2030.0; 2017.0) Australian Bureau of Statistics, 2001

30 Giallo R, d'Esposito F, Cooklin A, Mensah F, Lucas N, Wade C, et al. Psychosocial risk factors associated with fathers' mental health in the postnatal period: results from a population-based study. Soc Psychiatry Psychiatr Epidemiol 2013; 48: 563-73.

31 Matthey S. Are we overpathologising motherhood? J Affective Disord 2010 120: $263-6$ 